\title{
Adoption of sea cage farming of cobia (Rachycentron canadum) by fishermen self-help groups as a diversified livelihood option: A success story from Ramanathapuram District, Tamil Nadu, India
}

\author{
B. JOHNSON, A. K. ABDUL NAZAR, R. JAYAKUMAR, G. TAMILMANI, M. SAKTHIVEL, \\ P. RAMESHKÚMAR, G. GOPAKUMAR AND P. U. ZACHARIA* \\ Mandapam Regional Centre of ICAR-Central Marine Fisheries Research Institute, Mandapam - 623 520, Ramanathapuram \\ Tamil Nadu, India \\ ${ }^{*}$ ICAR-Central Marine Fisheries Research Institute, Kochi - 682 018, Kerala, India \\ e-mail: jsfaith@gmail.com
}

\begin{abstract}
The ICAR-Central Marine Fisheries Research Institute (ICAR-CMFRI) is the pioneer in developing the technology for cage fish farming in India. Cobia (Rachycentron canadum) grows relatively fast in cages and is very much suited for small scale mariculture to meet the alternate livelihood needs of fisherfolk. Mandapam Regional Centre of ICAR-CMFRI has developed the technology for breeding, seed production and farming of cobia in cages and organised training, and frontline/ participatory demonstration programmes which have aided in creating awareness about the techno economic viability of cage farming among the fisherfolk in Ramanathapuram District, Tamil Nadu. A survey was taken up among a sample of 75 members of fisher self help groups (SHGs) who had adopted cage farming of cobia, in order to assess their perception and attributes about the technology as well as the constraints faced by them. The study found that fast growth rate of cobia, shorter culture period, good farm gate price, high market demand, ease of farming near the seashore and seed availability were the important attributes which attracted the fishermen groups to take up the farming. The innovations introduced by the fishers in cage farming technology were also documented. Majority of the fishers stated, non-availability of seed during peak stocking season, high cost of pellet feed, fluctuating cost of low value fishes which are used as feed for cobia and poaching as major constraints in cage farming.
\end{abstract}

Keywords: Adoption, Cage farming, Cobia, Demonstration, Innovation

\section{Introduction}

Global aquaculture production during 2014 was 73.8 million $\mathrm{t}$, out of which, $36 \%$ (26.7 million $\mathrm{t})$ was contributed by mariculture. The share of finfish in mariculture production was 23.6\% (6.3 million ts) (FAO, 2016a). In recent years, seed production and farming of cobia (Rachycentron canadum) is rapidly gaining momentum in many Asian countries (Liao and Leano, 2007). In early 1990s. Taiwan introduced the cage culture of cobia (Liao et al., 2004) and at present nearly 23 countries have initiated seed production and farming of cobia (Nhu et al., 2011). The global aquaculture production of cobia during 2014 was 40,000 t (FAO, 2016b) which is almost double the production in comparison to the year 2005. Cobia production is also reported in the United States, Puerto Rico, Bahamas, Martinique, Belize, Brazil and Panama (Bennetti et al., 2008). India is a late starter in cobia research and the Mandapam Regional Centre (MRC) of the ICAR-Central Marine Fisheries Research Institute (ICAR-CMFRI) has developed the technology for breeding, seed production and farming of cobia in cages to meet the need of fisherfolk for carrying out small scale mariculture. Cage farming of cobia was experimented for the first time in India at the MRC of ICAR-CMFRI with hatchery produced fingerlings during 2011-12. The results of several demonstrations revealed that cobia is a lucrative species for sea cage farming and it can reach an average weight of 2 to $3 \mathrm{~kg}$ in 6 months and 4 to $8 \mathrm{~kg}$ in one year of culture period (Gopakumar et al., 2014). In America and the Caribbean, they could successfully grow cobia upto $6 \mathrm{~kg}$ in approximately 12 months in snapper farm (Benetti et al., 2010). Therefore cage farming of cobia fish is a comparatively better alternate livelihood option to sustain the income of the marine fishers' household.

The fish catch or harvest from marine capture fisheries in Palk Bay and Gulf of Mannar region of Tamil Nadu is in a stagnation phase over the last few years (Johnson et al., 2016). In order to address the issue of declining capture fisheries, the major management strategy followed worldwide is the adoption of fishing holidays. Another 
option is to ban trawling in a phased manner after making alternative livelihood options to the fisherfolk. Under this situation, the MRC of ICAR-CMFRI developed the technology for mariculture of cobia ( $R$. canadum) in cages as a viable livelihood option for the fisherfolk. As a result of the initiatives taken by the Research Centre, cage farming of cobia is being adopted in the Ramanathapuram District with the support of developmental agencies. In this context it has become necessary to know the socio-economic impact of cage farming. Hence, a study was conducted to assess the economic viability and technological perception about sea cage farming of cobia from all the fishermen groups who are presently involved in farming in Ramanathapuram District, south India.

\section{Materials and methods}

The study adopted expost-facto research design and primary data were collected from 75 members of the fisher self-help groups (SHGs) from six villages who had adopted cobia farming in Ramanathapuram District of Tamil Nadu. Data collection was done through interview method using a structured questionnaire and focus group discussions. The data obtained from respondents were systematically tabulated for the purpose of analysis and to arrive at meaningful conclusions.

\section{Tools for analysis}

The economic performance of cage farming of cobia was assessed by working out the annual fixed cost, operating cost, gross revenue, net profit and net operating income.

Net profit $=$ Gross revenueTotal cost of production)

Net operating income $=($ Gross revenue - Total operating cost)

Operating ratio $=($ Total operating costs $/$ Gross revenue $)$.......

Operating ratio relates variable costs to gross ncome and is an indicator of economic efficiency.

The list of attributes which attracted the fishermen groups to take up sea cage farming was ranked using Garrett's Ranking Technique. It provides the change of orders into numerical scores.

Garrett's formula (conversion of ranks into \%)

Percent position $=100 *\left(\mathrm{R}_{\mathrm{ij}}-0.5\right) / \mathrm{N}$

where, $R_{i j}=$ Rank given for $i^{\text {th }}$ factor by $j^{\text {th }}$ individual; $N_{j}=$ No. of factors ranked by $j^{\text {th }}$ individual.

The percent position of each rank was converted into scores by referring to the table (Garrett and Woodworth, 1969). The scores of each respondent were added together against respective factor. It was then divided by the total number of respondents for whom scores were added. In descending order, the mean scores for all the factors were arranged, ranks were given and the most important attributes were identified.

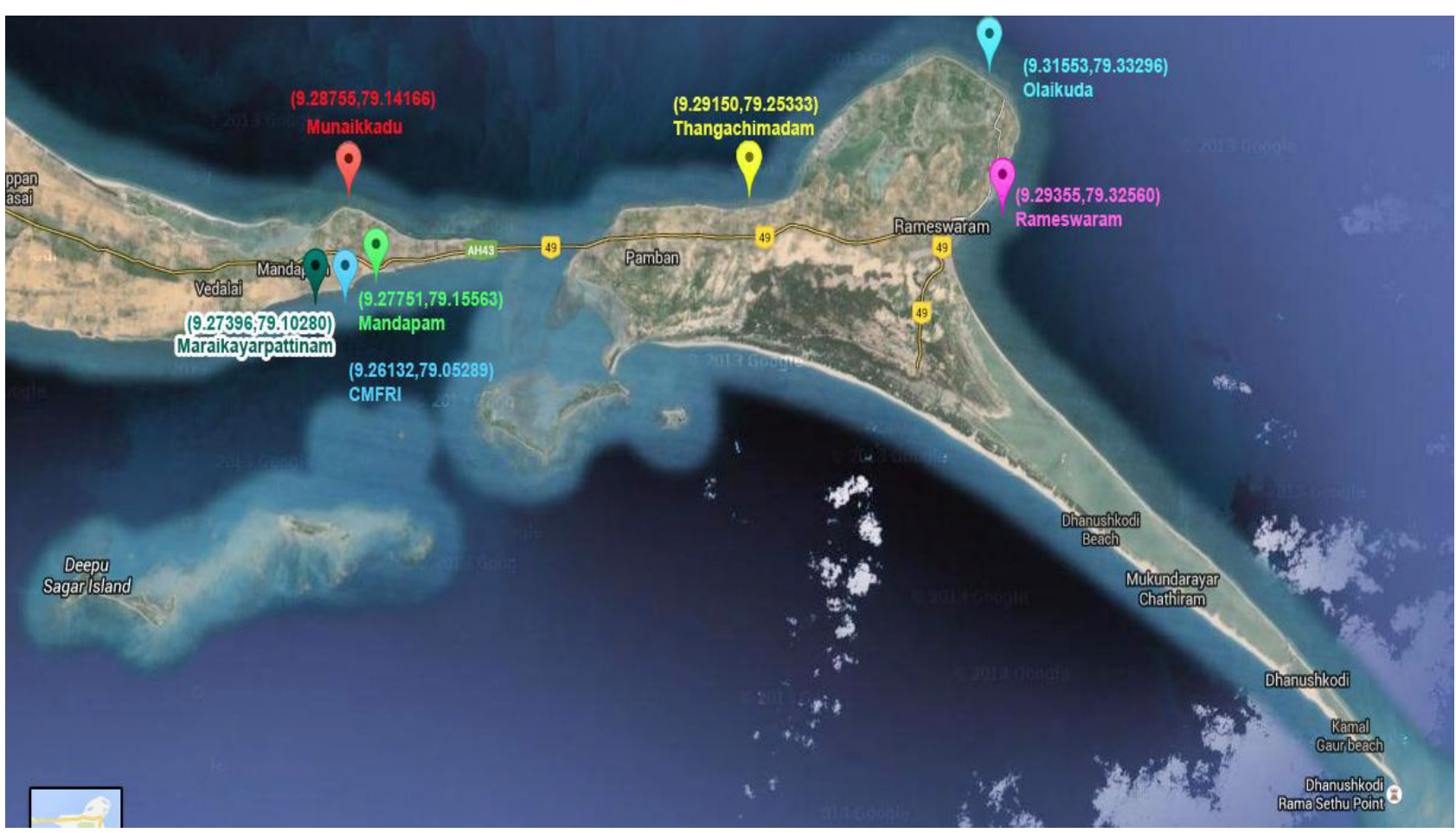

Fig. 1. Map showing the sites of cage farming of cobia in Ramanathapuram District 


\section{Results and discussion}

The techno-economic viability of open sea cage farming of cobia has been successfully demonstrated by the MRC of ICAR-CMFRI through Public Private Partnership (PPP) programmes during 2012-13. Realising the profits in sea cage farming, a fishermen SHG namely, Cobia Fisherman Welfare Association, from Rameswaram, took up sea cage farming with the technical support of MRC of ICAR-CMFRI. This was the first sea cage farming venture by a fishermen SHG, incurring all the expenditures involved. Their success motivated many fishermen groups to seek financial assistance from Ramanathapuram District Administration, to take up sea cage farming of cobia. Based on the requests received, the Government of Tamil Nadu mooted a new scheme under State Balanced Growth Fund to assist 10 SHGs to take up sea cage farming with $90 \%$ subsidy for two cages per group. As a result of the initiation taken by the MRC of ICAR-CMFRI, about 25 groups adopted the technology in this region (Fig. 2).

It is evident from the results presented in Fig. 3, that $71 \%$ of the fishers involved in cage farming belonged to the young age group (20-40 years), whereas only $29 \%$ of the fishers belonged to the middle age group (40-50 years). Hence it is very clear that the farming is mainly taken up by young and middle age group which is a good trend for the future.

\section{Sources of information on cage farming of cobia}

The information about the technology has spread to different parts of the District through individuals, groups and mass contact (Table 1). The major communication channel was training programmes and demonstrations organised by the research institute (ICAR-CMFRI) (65\%), followed by State Fisheries Department, Ramanathapuram $(20 \%)$; mass media $(10 \%)$ and individual contacts $(5 \%)$ (farmer to farmer approach).

Fishermen perception on sea cage farming of cobia

The fishermen groups expressed that the farming ideally could be carried out in the Gulf of Mannar and Palk Bay region during November-April and May-October,

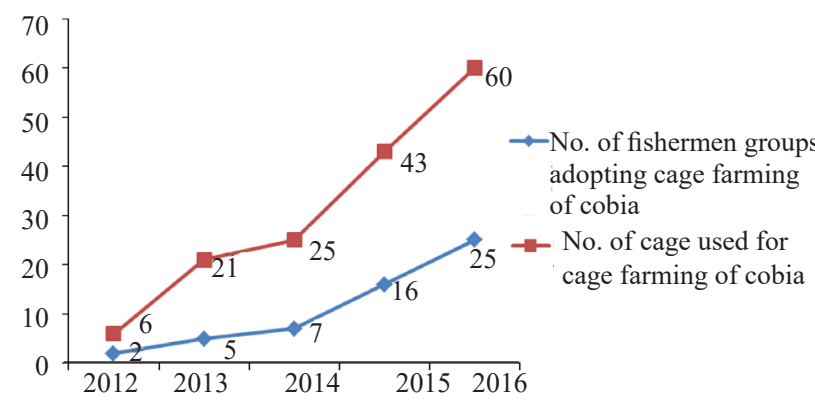

Fig. 2. No. of fishermen groups adopted sea cage farming of cobia in Ramanathapuram District with the technology support of ICAR-CMFRI

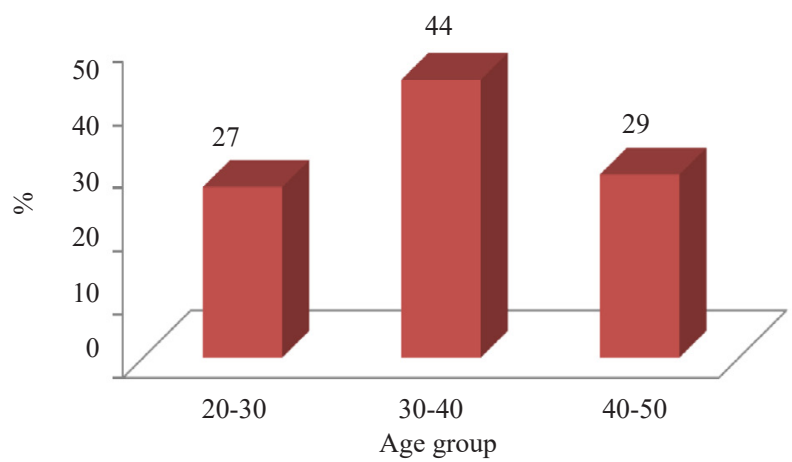

Fig. 3. Percentage of fishermen involved in cage farming based on age

Table 1. Source of communication to know about cage farming of cobia

\begin{tabular}{ll}
\hline Source & Percent \\
\hline Research Institute (ICAR-CMFRI) & 65 \\
Tamil Nadu State Fisheries Department & 20 \\
Mass media & 10 \\
(Radio/Internet/Regional TV channels) & 5 \\
Friends and neighbours & 5 \\
\hline
\end{tabular}

Adoption of sea cage farming of cobia

Garrett's Ranking Technique was used to identify and rank the attributes which attracted the fishermen groups to take up cage farming of cobia (Table 2). Relative advantage in the form of fast growth rate of cobia, easy farming methods and better economic returns, good farm gate price, availability of stockable size fingerlings, shorter culture period and high market demand were the important attributes ranked by the fishers, which motivated them to take up sea cage farming of cobia. The yield and economic returns from the farming was one of the major factors which contributed to the spread of this technology. Various agencies like research institutes (ICAR-CMFRI), Tamil Nadu State Fisheries Department and the Ramanathapuram District Administration played significant roles in successful adoption of this technology by the SHGs (Fig. 4, 5, 6, 7).

Table 2. Important attributes which attracted the fishermen groups to take up cage farming of cobia

\begin{tabular}{ll} 
& $(\mathrm{N}=75)$ \\
\hline Attributes & Garrett Rank \\
\hline Fast growth rate & $\mathrm{I}$ \\
Shorter culture period & $\mathrm{V}$ \\
Good farm gate price & $\mathrm{III}$ \\
High market demand & VI \\
Farming near the seashore & VII \\
Availability of stockable size fingerlings & IV \\
Easy farming methods and better economic returns & II \\
\hline
\end{tabular}




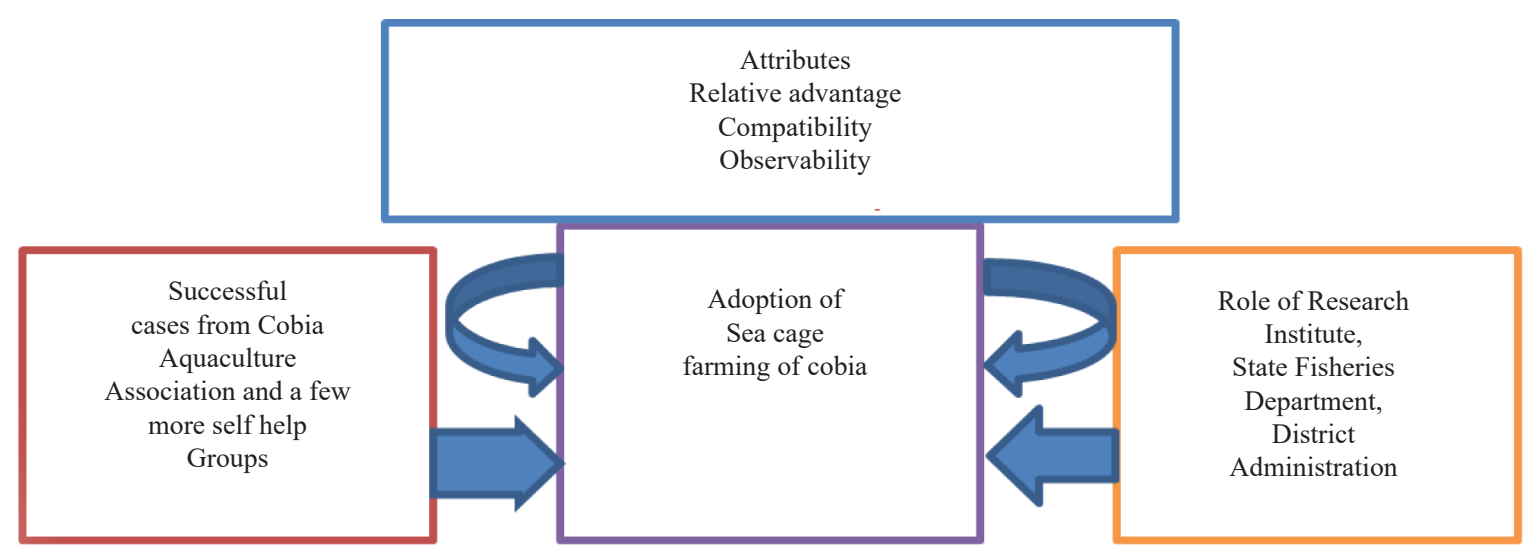

Fig. 4. Attributes and agencies that played a significant role in adoption of cage farming of cobia

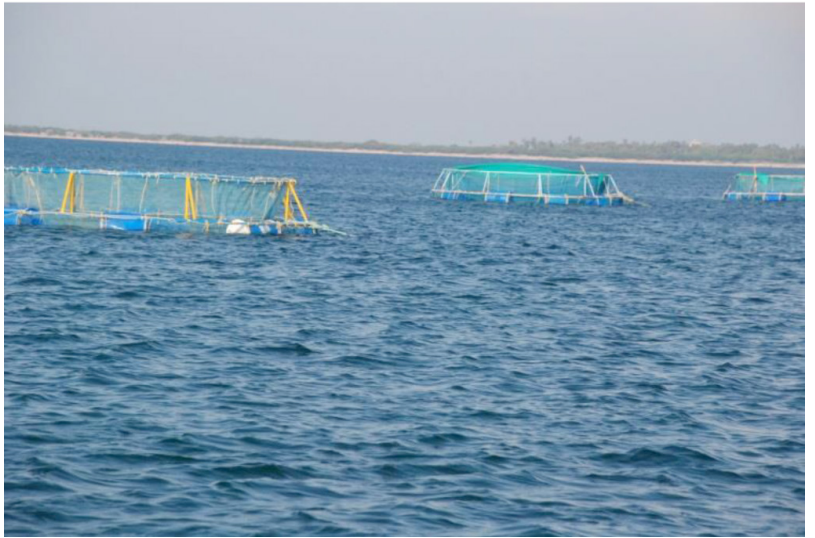

Fig. 5. Cage farming by a fishermen SHG, Thangachimadam

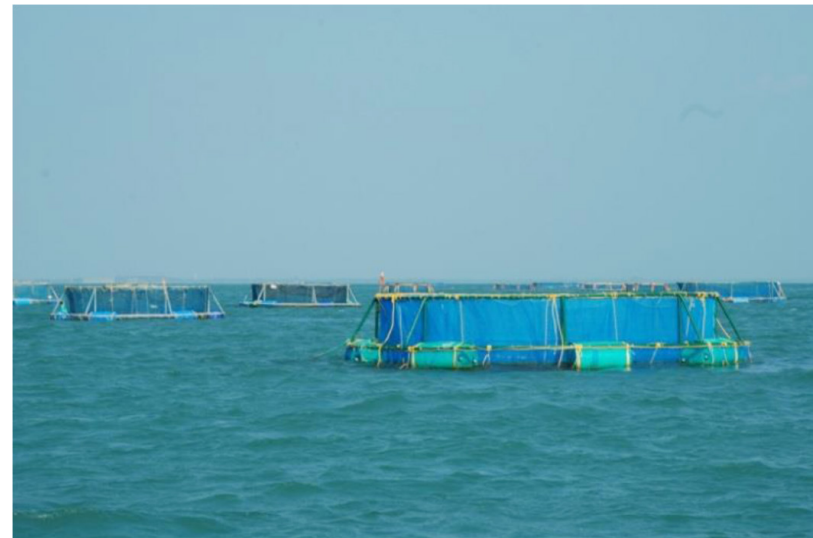

Fig. 6. Cage farming by Cobia Aquaculture fishermen Association

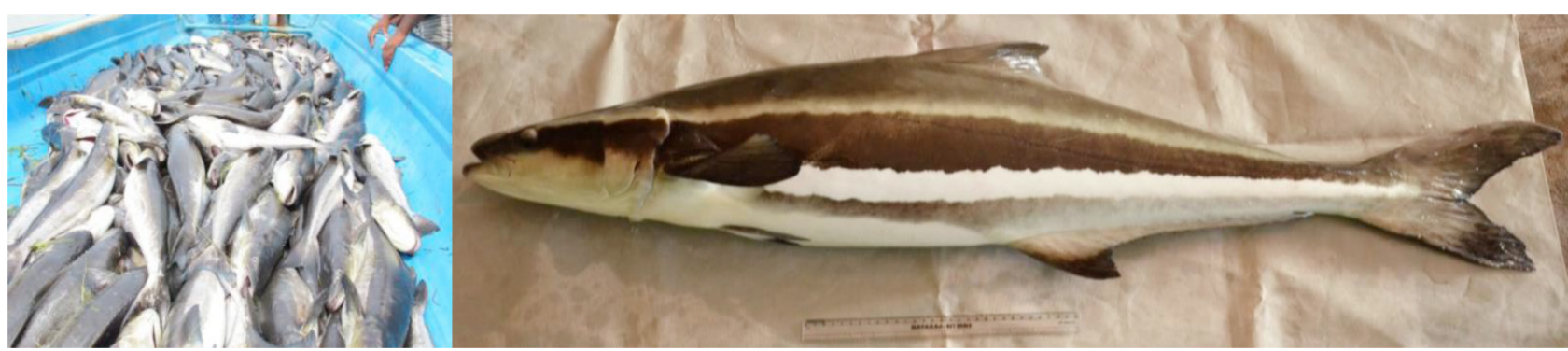

Fig. 7. View of harvested cobia

respectively. They also strongly agreed that sea cage farming can increase the marine fish production and can supplement the capture fisheries in future and provide additional income to their households. They agreed that it serves as a fish aggregating device and could observe fishes like Terapon, Carangids, Silverbellies, Rabbitfish and Mullets, near the cage site. The MRC of ICAR-CMFRI has successfully conducted the demonstration of Integrated Multi Trophic Aquaculture (IMTA) under participatory mode with a fishermen group at Munaikadu (Palk Bay), Tamil Nadu by integrating seaweed Kappaphycus alvarezii with cage farming of cobia. By witnessing and adopting IMTA, majority of fishers agreed that integrating the seaweed with cage farming of cobia could serve as bio-mitigation along with increased biomass production (Table 3).

\section{Innovations introduced by fisherfolk in cage farming}

The innovative modifications made by the fishers in cage farming technology were also documented during the study. In order to protect the barrels tied to the cage frame from the scorching sun, fishers placed gunny bags over the barrel (Fig. 8) which helped to enhance the economic life of the barrels. Farmers applied their idea of fibre moulding 
Table 3. Fishermen perception on sea cage farming of cobia $(\mathrm{N}=75)$

\begin{tabular}{ll}
\hline Statements & $\%$ \\
\hline Sea cage farming will contribute additional income to the household & 100 \\
Sea cage farming will supplement the capture fisheries & 40 \\
Sea cage farming may pave a way to reduce the fishing pressure & 70 \\
Sea cage farming may reduce the conflict among different sectors in fishery & 60 \\
Sea cage farming will address the problem of depletion of fishery resources & 55 \\
Sea cage farming serve as a fish aggregating device & 100 \\
Integrating the seaweed with cage farming of cobia will serve as bio-mitigation along with increased & 80 \\
biomass production &
\end{tabular}

at the weld joints in the cage frame (Fig. 9) which also helped to increase the life of the cage. Instead of epoxy coating over the cage frame, farmers applied rubber paint/ tar which prevented rusting of GI pipes (Fig. 10) and reduced cost incurred for coating by 20 times. In cage farming, poaching is one of the major issues and to prevent this, farmers kept battery operated lights in each cage (Fig. 11). These lights automatically go off during day time and glows during night time.

Economics of sea cage farming of cobia (for one cage and one crop)

The cost for making one $6 \mathrm{~m}$ dia GI (Galvanized Iron) cage is $₹ 1,25,000 /$-. It includes cost of ' $\mathrm{C}$ ' class GI pipe (1.5 inch dia), mooring materials and nets ( 2 inner

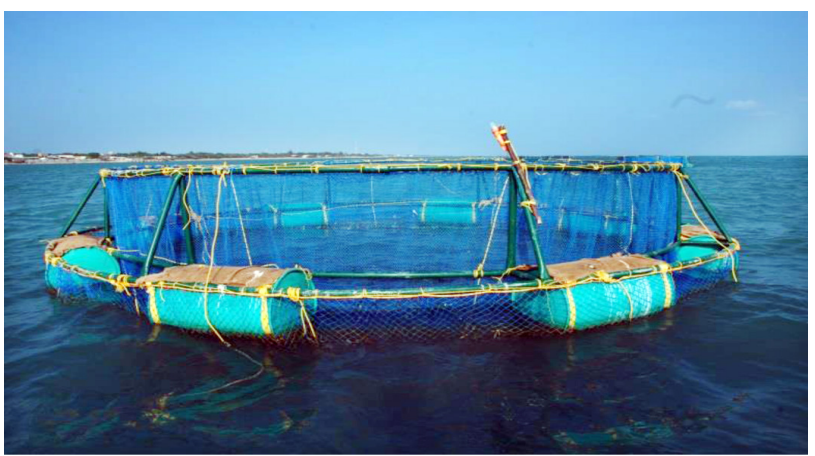

Fig. 8. Gunny bags placed over the barrels

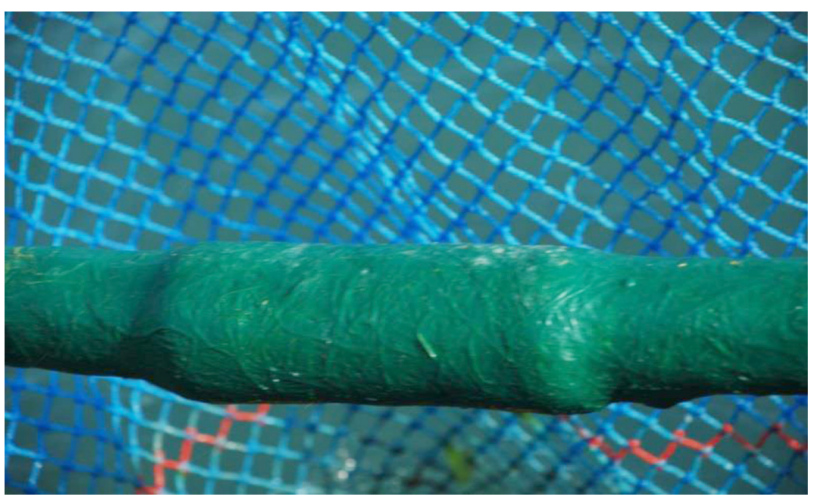

Fig. 9. Fibre molding at the weld joints

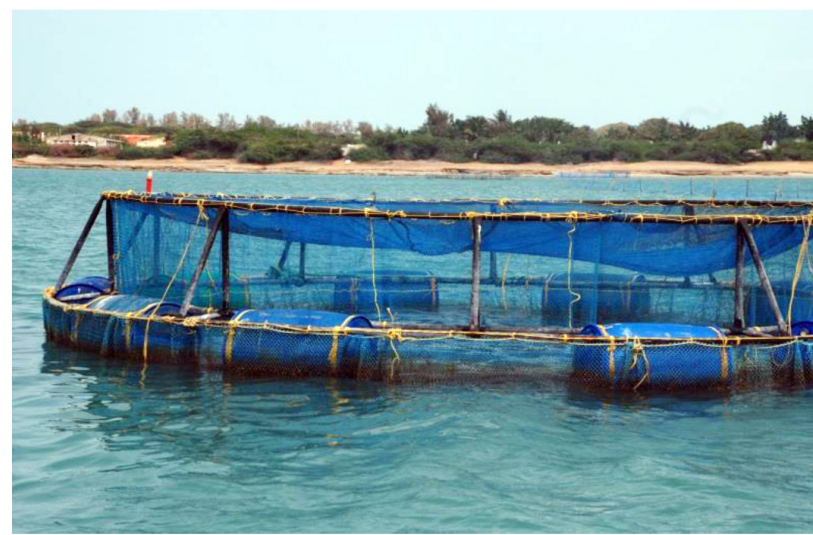

Fig. 10. Tar coating over the GI Pipes

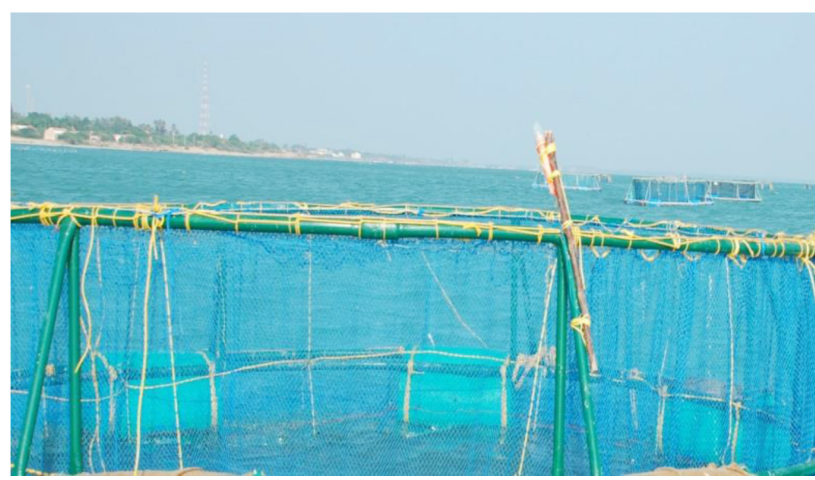

Fig. 11. Provision of battery operated lights in the cage

net and one outer net with ballast pipe). The variable costs of production was $185 \mathrm{~kg}^{-1}$ and sale price realised was ₹300 $\mathrm{kg}^{-1}$ (Table 4). An yield of 1,950 kg was obtained in seven months and gross revenue of ₹5.85 lakhs was obtained. The income over operating cost was ₹2.25 lakhs (Table 4). The average operating ratio for sea cage farming of cobia was 0.62 , which implied that $38 \%$ profit was realised in cage farming.

Constraints in sea cage farming of cobia as perceived by the fishermen

Most of the fishers stated that non-availability of seed during peak stocking season $(90 \%)$, high cost of formulated 
Table 4. Economics of sea cage farming of cobia during 2016-17 (for one cage and one crop)

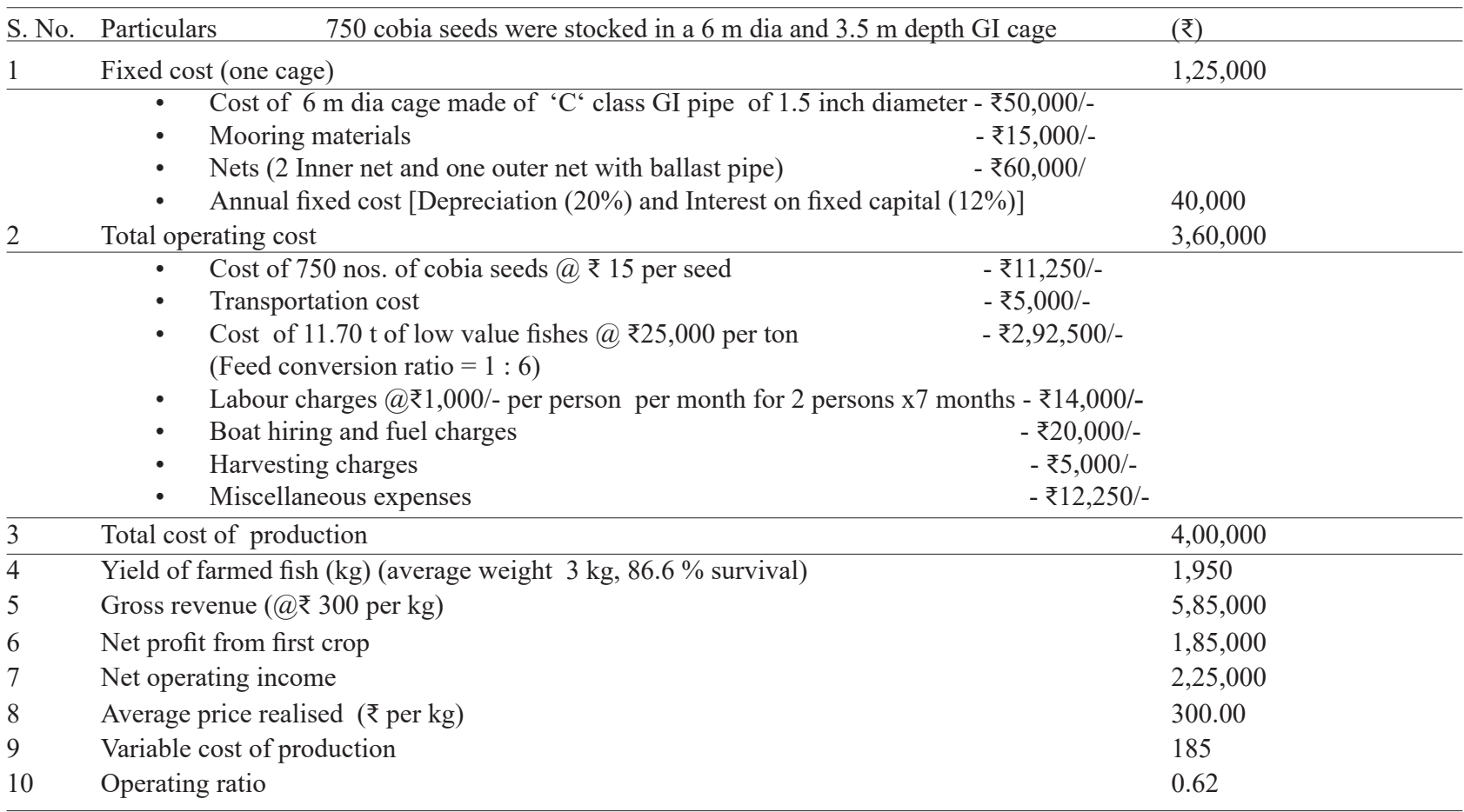

pellet feed (90\%), fluctuating cost of low value fishes used for feeding fishes $(90 \%)$ and poaching $(80 \%)$ as the major constraints (Table 5). Two-fifth of the fishers expressed that farm gate price of harvested cobia was comparatively less during the months of October-December (₹210- 230 per $\mathrm{kg}$ ) as non-vegetarian consumption is less during these months owing to many traditional festivals.

Adoption of sea cage farming of cobia is in take off stage and may pave a way to reduce the fishing pressure and contribute additional income to the fisher household. Research institutes, developmental agencies, private hatcheries and feed mills should address the issue of seed and feed. Integrated Multi Trophic Aquaculture (IMTA) as a bio-mitigation can be adopted wherever possible. It was found that this practice was an eco-friendly option with sustainable income to the coastal fishers.

Table 5. Constraints on sea cage farming of cobia as perceived by the fishermen

\begin{tabular}{lc}
\hline Attributes & $(\mathrm{N}=75)$ \\
\hline $\begin{array}{l}\text { Non-availability of cobia seeds during peak stocking } \\
\text { season }\end{array}$ & 90 \\
Non-availability of low value fishes during ban period & 90 \\
Fluctuating cost of low value fishes & 90 \\
Poaching & 80 \\
Farm gate price of harvested cobia is comparatively less & 40 \\
during the months of October - December & \\
\hline
\end{tabular}

\section{Acknowledgements}

The authors are thankful to the Director, ICARCMFRI, Kochi for guidance and support. The study was conducted with financial support from the ICAR-NICRA project (2020600006).

\section{References}

Bennetti, D. D, Mehmet, R., Bruno, S., Brian, O. H., Aaron, W., Ronald, H., Ian, Z., Jose, A. R., Bristol, D., Donald, B., Kevin, P. and Fernando, C. 2008. Advances in hatchery and grow-out technology of cobia, Rachycentron canadum (Linnaeus). Aquac Res., 39: 701-711. https://doi. org/10.1111/j.1365-2109.2008.01922.x.

Benetti, D. D, Brian, O. H., Jose, A. R., Aaron, W. W., Christopher, M. and Refik, O. M. 2010. Growth rates of cobia (Rachycentron canadum) cultured in open ocean submerged cages in the Caribbean. Aquaculture, 302: 195-201.

FAO 2016a. FishStat $J$ version 3.01: Universal software for fishery statistical time series: Aquaculture production 1950-2014; Capture production 1950-2014. Fisheries and Aquaculture Department, Fishery Information, Data and Statistics Unit, Food and Agriculture Organisation, Rome, Italy.

FAO 2016b. The state of world fisheries and aquaculture 2016, Contributing to food security and nutrition for all. Food and Agriculture Organisation, Rome, Italy, 200 pp. http:// www.fao.org/3/a-i5555e.pdf.

Garret, H. E. and Woodworth, R. S. 1969. Statistics in psychology and education. Vakils, Feffer and Simons Pvt. Ltd., Mumbai, 329 pp. 
Gopakumar, G., Abdul Nazar, A. K., Jayakumar, R., Tamilmani, G. and Sakthivel, M. 2014. Strategies and way forward to augment seafood production through finfish mariculture. Mar. Fish. Infor. Serv., T \& E Ser., 219: 3-7.

Johnson, B., Nazar, A. K. A. and Jayakumar, R. 2016. Analysis of training effectiveness of marine ornamental fish culture training programmes. Mar. Fish. Infor. Serv., T and E Ser., 229: 3-7.

Liao, I. C. and Leano, E. M. 2007. Cobia aquaculture: Research, development and commercial production. Asian Fisheries Society, Manila, Philippines; World Aquaculture Society,
Louisiana, USA; The Fisheries Society of Taiwan and National Taiwan Ocean University. Keelung, Taiwan, 178 pp.

Liao, I. C., Huang, T. S., Tsai, W. S., Hsueh, C. M., Chang, S. L. and Leano, E. M. 2004. Cobia culture in Taiwan: current status and problems. Aquaculture, 237: 155-165. DOI: 10.1016/j.aquaculture.2004.03.007.

Nhu, V. C., Nguyen, H. Q., Le, T. L., Tran, M. T., Sorgeloos, P., Dierkens, K., Reinertsen, H., Kjorsvik, E. and Svennevig, N. 2011. Cobia, Rachycentron canadum aquaculture in Vietnam:Recent development and prospects. Aquaculture, 315: 20-25.

Date of Receipt : $\quad$ 07.02.2017

Date of Acceptance : $\quad$ 18.06.2019 